\title{
THE LIFE AND SERVICES OF MAXIME BÔCHER.*
}

Maxime Bôcher was born in Boston, August 28, 1867, and died at his home in Cambridge, September 12, 1918. His father, Ferdinand Bôcher, was the first professor of modern languages at the Massachusetts Institute of Technology. Shortly after Mr. Charles W. Eliot, at that time professor of analytical chemistry and metallurgy in the same institution, became President of Harvard University, Professor Bôcher was called to Cambridge (in 1872) and for three decades was one of the leading teachers in the faculty of Harvard College. He was an enthusiastic collector of books. His library, which was divided after his death, formed the nucleus of the library of the French Department and yielded, furthermore, a welcome accession to the library of the Cercle Français; but its most important part, the valuable Molière and Montaigne collections, passed intact to the library of Harvard College. It was through the generosity of Mr. James Hazen Hyde, who bought the whole library, that such a disposition of the books became possible.

As a college teacher Ferdinand Bôcher is remembered by many men for whom college life in their student days offered varied attractions, as one who helped them to see and enjoy the beauty of language and literature.

Maxime's mother was Caroline Little, of Boston. She was of Pilgrim ancestry, being a descendant of Thomas Little, who joined the Plymouth Colony in its early days and in 1633 married Anne Warren, the daughter of Richard Warren, who came in the Mayflower.

Thus Bôcher's boyhood was passed in a home in which much that is best in the spirit and thought of France was united with the traditions and intellectual life of New England. He attended various schools, both public and private, in Boston and Cambridge; but it was to the influence of his parents that the awakening of his interest in science was due.

He graduated at the Cambridge Latin School in 1883 and took the bachelor's degree at Harvard in 1888. Then followed three years of study at Göttingen, where he received the degree

* For a critical estimate of Bôcher's scientific work the reader is referred to Professor Birkhoff's article in the February BuLletin. 
of doctor of philosophy in 1891, and at the same time the prize offered in mathematics by the philosophical faculty of the university. From 1891 till his death he was a member of the Department of Mathematics in Harvard University. He married Miss Marie Niemann, of Göttingen, in 1891. His wife and three children, Helen, Esther, and Frederick, survive him.

His college course was a broad one. Outside of his main field of mathematics and the neighboring field of physics he took a course in Latin and two courses in chemistry, and courses in philosophy under Professor Palmer, in zoology under Professor Mark, and in physical geography and meteorology under Professor Davis; and it is interesting to note that in his senior year, beside his work in mathematics, he elected Professor Norton's course in Roman and mediæval art; a course in music with Professor Paine, and an advanced course in geology with Professor Shaler and Professor Davis, and Professor (then Mr.) Wolff. In his senior year he also competed for a Bowdoin Prize, and the committee awarded him a second prize for an essay on "The meteorological labors of Dove, Redfield, and Espy." At graduation he received the bachelor's degree summa cum laude, with highest honors in mathematics, his thesis being "On three systems of parabolic coordinates." A travelling fellowship was granted him, and it was twice renewed.

Bôcher's education was not confined to the courses he took. $\mathrm{He}$ was a reader and a thinker, and he was interested in many of the general questions of the day. But generalities did not satisfy him; he demanded of himself that he know precisely the essential facts. His critical powers were early cultivated, and he was endowed with good judgment. In debate, he was able to marshall his facts with rapidity, to arrange them strategically, and to make his point with clearness. In rebuttal, he was an expert.

I recall an incident which occurred at a meeting of the M. P. Club* in the early nineties, and which shows the characteristics last mentioned. Professor Woods had given an interesting talk on surfaces which are applicable to one another, and had illustrated his subject with models from the Brill collection in the mathematical library of the Institute.

* This club was formed in the eighties for the purpose of bringing the members of the departments of mathematics and physics at the Massachusetts Institute of Technology and Harvard into closer relations. 
One of the members of the Club was a physician, whose interest in mathematics had been kindled by Benjamin Peirce, and who, though not a profound mathematician, nevertheless delighted to read mathematics, much as our ancestors read their Horace. He asked a question which was based on his doubt whether parallel lines, in any logically necessary interpretation of the words, "meet at infinity." Now, there was also present a learned professor from another institution, and it pleased him to answer the doctor from a mighty height. But, in his answer, he was thinking only of projective geometry, and his arrogance made Bôcher indignant. "That is not true in the geometry of inversion," the latter replied. "That is not geometry," was the professor's scornful rejoinder. "It is what Klein calls geometry," came back quick as a flash. "Oh, Klein is not a geometer." This was the professor's last shot. In two brief statements of facts the youthful Bôcher had put his opponent into the position of asserting that the man who wrote the "Vergleichende Betrachtungen über neuere geometrische Forschungen" was not a geometer!

Above all, Bôcher was sincere. He liked to argue and to defend a position; but when the game was over, it was the truth which had been brought out that pleased him most.

He distrusted popular conclusions, even when the public was a learned one. It was facts, not views, that he sought, and his own intellect was the final arbiter. The following incident is characteristic of his type of mind. When his last sickness was developing, he needed a physician, and the wellknown doctors were away in the war. He made inquiries one day regarding a young practitioner of rising fame, with whom Professor Birkhoff had recently had some experience. The latter said in closing, "I must add, however, that Dr. - is pessimistic. He is given to taking a gloomy view of the condition of his patients." "I do not care whether he is pessimistic or not," was Bôcher's reply, "if the diagnosis is correct."

The later years of his life were not happy ones. Even as far back as the winter of 1913-14 his strength was frequently inadequate for the daily needs. He never complained; in fact, he was unwilling to talk about himself even for a moment. But for one whose demands on himself were such as Bôcher's it must have been a severe trial not to achieve the full measure of results of which the mind was capable and for which it longed to work. 
He was a Puritan, and with the virtues he had also the faults of the Puritan. There was no place in his world for human weakness, even though the individual had done his best. A reverence for human beings because of their struggles to attain higher things was lacking in his make-up; he respected only results. And so, to many a man who came into personal relations with him in his profession, he seemed cold and unsympathetic. What the stranger, however, too often failed to observe was that Bôcher applied the same stern standards to himself. Why should others expect to fare better?

In order to understand the mathematical work of Bôcher it is well to consider at the outset the state of the science as he found it. The nineteenth century was an era of intense mathematical activity, not in one land alone, but among all the peoples which were leaders in scientific thought. If it was not reserved for mathematicians to make formal discoveries coordinate in importance with those which formed the crown of the discoverers and early developers of the calculus, it is none the less true that mathematical imagination never played more freely, not only in geometry and algebra, but also in analysis and mathematical physics.

But mathematics was no longer in its infancy. In the great age just preceding the French revolution, a mathematician could know, at least in its essential parts, all that had been done in the science up to that time, just as, a century earlier, the man of learning was conversant not only with mathematics and physics, but also with the principal systems of philosophy. With the enormous expansion of the subject matter, or detailed theories, which grew up and flourished with amazing virility in an age characterized by its struggle for intellectual freedom, a point had been reached where it seemed as if mathematics was destined to disintegrate through the very volume of its scientific content.

It was at this time - the eve of the Franco-Prussian Warthat two youths met in Berlin, who were to become leaders in mathematical thought-Felix Klein and Sophus Lie. True, these men were remote from each other in their specific mathematical interests, and their life work lay in different fields. Lie built up a consistent, harmonious theory which both yielded new results and brought old ones under a common point of view. With Klein it was not a question of developing 
a method for its own sake, or even of caring for method, except in so far as he was thus able to uncover the natural interrelations of parts of the science which hitherto had seemed foreign to each other.

A pupil of Clebsch and Plücker, Klein early became acquainted with the geometric advances that group themselves about the names of Monge and Poncelet, of Steiner and von Staudt. In analysis, the theory of functions, as developed by Cauchy and his followers, was already beginning to come into its own. Göttingen was filled with the traditions of Riemann, whose life touched fingers with that of Klein. In algebra, Galois's contributions were still new, and Hermite and Kronecker had, hardly more than a decade previously, solved the general equation of the fifth degree.

Klein's first great contribution toward unifying apparently unrelated disciplines was the Erlanger Programm of 1872 mentioned above, on a Comparative Consideration of Recent Advances in Geometry. It was here that he set forth projective geometry, not as an isolated science-geometry, par excellence-but rather as one (true, the most important) of a whole array of geometries, of which, in particular, the geometry of reciprocal radii, or inversion, is a member; for the basis of each of the geometries is the group of transformations which leave invariant certain configurations, and two geometries are essentially equivalent when their groups are isomorphic and their elements stand to each other in a one-to-one and continuous relation.

It would have been easy for Klein at this stage to found a school on the basis of postulates. If the thought ever occurred to him, he rejected it both because the results to be obtained would lack important mathematical content and because he instinctively sought the specific interrelations of seemingly distinct branches of mathematics, in order that one might yield new theorems, or illumine old ones, in the other.

It was to an environment imbued with such traditions. that Bôcher came, when he was matriculated at Göttingen in the fall of 1888 . His previous training at Harvard had prepared him to enter at once on advanced work. In the last year of his college course, as has already been said, he had written a thesis on parabolic coordinates. Klein was beginning the continuation of his lectures on the potential function, 
and these were followed by his lectures on the partial differential equations of mathematical physics, and on the functions of Lamé. He also lectured at this time on non-euclidean geometry.

It is seldom that a student is brought into such vital contact with the chief branches of mathematics as was the case with Bôcher. His thesis was on Developments of the Potential Function into Series, a subject which he shortly after worked out at greater length in a monograph. Though the leading ideas had been set forth by Klein in his lectures, nothing could be further from the truth than to think that Bôcher merely elaborated some details. The subject was an exceedingly broad one. It required for its treatment not so much a specific knowledge of the theory of the potential, although Bôcher was thoroughly equipped on that side; nor even familiarity with the geometry of inversion, of which he had made himself master; but rather, the power to carry through a piece of detailed analytic investigation with accuracy and skill, and with this work Klein occupied himself only in the most general way. Nor was it a question of the proof of convergence for the series obtained. Indeed, these proofs have not as yet been given, though recent advances have been made by Hilbert with the aid of integral equations. The importance of the dissertation in its influence on Bôcher lay largely in the fact that it stimulated his interest in mathematical physics, in pure geometry, in algebra, and in applied analysis. More precisely, beside the general geometrical ideas and theories above mentioned, the specific study of the Dupin cyclides and their generalization by Laguerre, Moutard, and Darboux was involved.* Through the method of elementary divisors, he was led to examine in detail a chapter in pure algebra, together with its application in more than a single field in geometry. From the formal solution of the first boundary value problem for Laplace's equation by means of series to the study of boundary value problems for the partial differential equations of physics of other than the elliptic type and the treatment of these problems by the more recently developed methods of integral equations, was a natural course. Throughout all his work, the total linear homogeneous differential equations of the second order were a constant source of further investiga-

* An appreciation of Bôcher's contributions in this field will be found in Professor Birkhoff's article. 
tions, both by himself and by his pupils, and his last great published work, the Paris lectures, is in this field.

In the fall of 1891 Bôcher began his career as university teacher, being appointed to an instructorship in the department of mathematics of Harvard University. It is the practice of that department to give to each of its members an elementary, an intermediate, and an advanced course. Bôcher's teaching, both elementary and advanced, was successful from the beginning. He did not have to "learn to teach"; teaching came to him naturally. Doubtless he was aided in this direction by the example of his father and the family traditions, for his mother had also been a teacher; nor were his parents the only ones of the immediate family who had been engaged in that profession. The standards of clearness, both in thought and expression, which characterize French men of letters and science, Bôcher made his own, not by a conscious effort, but through an inner driving force which made it a part of his very nature to find suitable expression for his ideas. "He never tried to be clear," Major Julian Coolidge wrote me this fall, "because his constitution was such that he did not know how to express his thoughts in any but the clearest form." I would not, however, be understood as saying that he achieved his success as a teacher without effort. He gave careful thought to the preparation of all his instruction, both as regards the choice of material and the presentation; but he was able to do this without serious loss of time or energy.

His intermediate course in the first year of his teaching was on modern geometry. Professor Byerly had already developed this course to a point which gave it an important place in the undergraduate instruction. The outlook on geometry which Bôcher had acquired under Klein enabled him to make the course still more effective as an introduction to the ideas and methods of the higher geometry of the present day. He gave this course repeatedly (about every other year) during the whole period of his service, and he was engaged in the preparation of his lectures for publication at the time of his last illness.*

* Since this course meant so much to Professor Bôcher, the reader will be interested in his description of it in the Departmental Pamphlet:

"3. Introduction to Modern Geometry and Modern Algebra.

The subjects considered in this course are:

(a) Affine Transformations; The use of Imaginaries in Geometry; 
In the minds of some readers the word lecture in connection with a sophomore course may cause doubts as to the efficiency of the instruction. The objection is raised that sophomores cannot take notes and get only vague outlines of ideas which they cannot develop further. It must be remembered, however, that this course is a free elective, and that it is chosen by men who have interest in mathematics and capacity for its pursuit. Moreover, frequent exercises are assigned (as a rule, daily) which range all the way from simple tests on the essentials to problems whose solution is possible only for students who really dominate the methods. These problems are corrected and returned to the student.

So much by way of apology. Let me now say, with all aggressiveness, that it was largely to the lecture method that both Professor Bôcher and I owed the awakening of our interest in mathematics when we were undergraduates in Harvard College. The instruction thus imparted stimulated thought, and the exercises assigned developed power-the power to obtain new results, even in the undergraduate stage. It was with exultation that we followed courses given by this method, in which our mathematical powers grew before our very eyes. In saying this, I am also stating Bôcher's views, for he repeatedly expressed himself on this subject in conversation.

Bôcher's advanced course in the first year of his professional life took the form of a seminary, the subject being curvilinear coordinates and functions defined by differential equations. A part of the instruction consisted of formal lectures on the latter topic, and he thus began, even at that early date, to treat topics in a field of analysis in which he was to become eminent.

In the eighties, a number of American students of mathematics from various colleges went abroad, chiefly to Germany, for further instruction and guidance in mathematics. When

Abridged Notation; Homogeneous Coordinates; Intersection and Contact of Conics; Envelopes; Reciprocal Polars; The Parametric Representation of Straight Lines and Conics; Cross-Ratio; Projection and Collineation; Inversion.

(b) Complex Quantities; The Elements of the Theory of Equations; Determinants; The Fundamental Conceptions in the Theory of Invariants. The portion of the course devoted to the geometrical subjects $(a)$ will be two or three times as extensive as that devoted to the algebraical subjects $(b)$, and the relations between these two parts of the course will be emphasized." 
they returned, some of them became university teachers and strove, so far as in them lay, to give to their students advantages like those to be found in Europe at a mathematical center. Bôcher was one of this latter group. With rare discernment for problems of importance, on which advanced students might work with a reasonable prospect of success, he gave himself unstintingly to the task of helping such students to carry through pieces of investigation and to put their results into good form. He did not foster work on the part of his students by artificial means-by high praise or an appeal to ambition. He felt that the student must be possessed of idealism and must, of his own nature, find satisfaction in scientific activity; otherwise, the writing of a doctor's thesis would represent only a forced growth. At times, it seemed to the beginner in research that he was unappreciative. But the student who had capacity for mathematical investigation and loved the science found an open ear and a ready response when he came with a contribution of real scientific merit, be that contribution in itself large or small.

The awakening in the science of mathematics in this country was followed at once by the springing up of the New York Mathematical Society, which shortly after became the American Mathematical Society. Of the latter Bôcher early became a member, and he took a keen interest in its affairs, contributing to its BULLETIN and participating in all its activities. He and Professor Pierpont were the speakers at the first Colloquium given by its members-at Buffalo, in 1896. When the establishment by the Society of a journal devoted to research was under discussion, it was through his insight that a way out of the difficulties which seemed insurmountable was found. Among the older members of the Society were those who saw in the establishment of such a publication an unfriendly act toward the American Journal of Mathematics. At a meeting of about a dozen mathematicians, held in New York in the fall of 1898 to discuss the question, this view was represented by the late Dr. McClintock. Bôcher asked him if he saw any objection to the Society's publishing its Transactions. To the surprise of all, there came a prompt answer in the negative. The difficulty was overcome. The Society might not establish the "Journal of the American Mathematical Society," but it might publish the "Transactions of the American Mathematical Society"! 
Producers of mathematical research are, as a rule, not facile in their expression. When one has been engaged in the protracted study of a problem, the early difficulties and the underlying ideas become obscured through familiarity with the facts, and the writer produces a paper hard to read. The early editors of the Transactions labored, and not without success, to impress on the contributors the importance of making easily accessible to the reader the main results and methods of the paper, and of showing the relation of the investigation to previous work. It was here that Bôcher's power as a critic was of great service. But a critic, to be helpful in such work, must be constructive. How admirably Bôcher was adapted for this undertaking, could not be shown more strikingly than by the opening paragraphs of his Dissertation, which are a model of what an introduction to a scientific paper of wide scope should be. He was not a member of the first editorial boards, for at that time the Annals of Mathematics had just been taken over by Harvard University, and he was doing similar work for that journal. But from the start he was in close touch with the editors of the Transactions, and his views on general questions and specific papers were helpful to them. Later, he served for two terms (with the exception of one year, in which he was absent from the country) on the editorial board.

He was president of the Society from 1908 to 1910. For his presidential address he took as the subject: "The published and unpublished works of Charles Sturm on algebraic and differential equations." He delivered the address in Chicago. The meeting will live in the memories of all who were present, especially in those of the eastern colleagues, as a particularly delightful occasion.

Bôcher's judgment of men, too, was sound, and those who had occasion to discuss nominations or appointments with him felt that a decision which had his approval could be trusted.

The breadth of Bôcher's knowledge of mathematics was accompanied by a true sense of perspective. His estimate of the importance of an investigation was extraordinarily sound. In his own work, this quality of mind was both a help and a hindrance. It helped him to choose well the problems which he and his students were to study. It can fairly be said that Bôcher never occupied himself with an unimportant problem. 
On the other hand, the enthusiasm just of doing things in mathematics - the joy of living, so to speak - gives to one's mental work a momentum which carries it over the obstacles of disappointment and discouragement, when one effort and another fail to yield results, and along with much which is valueless for others there come, now and then, contributions worthy of a lasting place in the science. I will not say that Bôcher was without such enthusiasm; but he did not show it in his intercourse with others. His nature was reserved. He would not talk on personal matters relating to himself, and this disinclination extended even to his scientific work.

He was, however, glad to discuss the work of others with them. He was quick to grasp the central idea and often could express it more clearly than its author. The early meetings of the Society were prized by those who attended them less for the formal papers presented than for the informal gatherings in the evening or about the breakfast table. It was here that the real mathematical discussions took place, and who of those who had the rare good fortune to be associated with that little group will ever forget what Bôcher was to us in those days? His special field was analysis; but so broad were his sympathies and his learning that he usually took a leading part in the discussions. His criticism was always helpful, often constructive, and freely given in the finest spirit.

We have mentioned the Presidential Address. At the St. Louis Congress, in 1904, he delivered an address on "The fundamental conceptions and methods of mathematics." $\mathrm{He}$ gave a lecture at the Fifth International Congress of Mathematicians, at Cambridge, England, in 1912, his subject being: "Boundary problems in one dimension." In 1913-14 he was exchange professor at Paris. His opening lecture was of a general nature and was entitled: "Charles Sturm et les mathématiques modernes."

It was not until late that Bôcher occupied himself with the writing of text-books. He had published some expository articles, chief among which were the pamphlet on "Regular points of linear differential equations of the second order," Harvard University Press, 1896; an article on "The theory of linear dependence," Annals of Mathematics, (2) 2 (1901) and an "Introduction to the theory of Fourier's series," ibid., (2) 7 (1906); three years later he wrote Tract 10 of the Cambridge (England) series, entitled: "An introduction to the study of integral equations." 
The Algebra appeared in 1907. Hitherto, books on algebra in the English language had been of the Todhunter type, or they had followed the lead of Salmon, through whom "Higher Algebra" came to mean specifically the study of the algebraic invariants of a linear transformation. What the mathematician needed to know of linear dependence and the theory of linear equations, of polynomials (factorization, resultants, and discriminants), the reduction of one or of two quadratic forms to normal type (including, perhaps, the rudiments of elementary divisors) he had to pick up as best he could. In no one place were they treated systematically, and most of the treatments were inadequate for the present day needs of the science.

Bôcher filled this gap in a thoroughly satisfactory manner. The Algebra was received with appreciation, both in this country and abroad, and at the suggestion of Professor Study a German translation was prepared. How thoroughly the work had been done originally is seen from the fact that practically no revision was needed.

The Trigonometry (written jointly with Mr. Gaylord) and the Analytic Geometry are so widely and intimately known as to require no detailed comment. These books present elementary subjects in a form accessible for elementary students, and treat them with a degree of accuracy, elegance, and perspective seldom attained by writers of text-books.

I have spoken of Klein's efforts to unify mathematics. Bôcher's aim may be described by saying that he strove to clarify mathematics. To illustrate by a single, but important example, let me consider the theory of functions of a complex variable. In the early nineties there were two distinct schools, and neither sought to aid or to learn from the other. Cauchy based his theory on the calculus of residues, obtaining Taylor's theorem as a corollary. With Weierstrass and Méray power series formed the foundation. The integral was more pliable and better adapted to the needs of the subject. But the questions which the critics had raised regarding limits, and in particular the reversal of the order in a double limit, had not been settled in a satisfactory manner for integrals, and even for series they were ignored by the writers of the Cauchy school. On the other hand, Weierstrass restricted his infinite processes to differentiation and power series. His treatment was rigorous, but clumsy, and the whole theory took on a formidable aspect. 
Riemann's methods were thought of less as forming an independent theory than as yielding an important mode of treatment for certain classes of functions; e. g., the algebraic functions and their integrals, and the functions defined by linear differential equations or their resolvents; notably, the $P$-function and the automorphic functions.

In 1893-94 Bôcher gave for the first time in his career the introductory course on the theory of functions of a complex variable, and in the same year he repeated his course on functions defined by differential equations, laying stress on the complex theory. The subjective effect is obvious. For him, it could not be a question of developing the general theory of functions as an end in itself. He was interested in the theory as a tool-as a means of investigating, for example, the functions defined by differential equations. But he was interested in improving the tool, in developing better machinery than had come down to us. He cared nothing for the schools. $\mathrm{He}$ sought the simplest method for solving each problem.

Of course, he was rigorous. But for him, rigor was not a strait-jacket. For him, rigor was not something superimposed on a proof, already satisfactory to a normal mind, by a certain cult of mathematicians. If a proof was not rigorous, it was not clear-it had not succeeded in analyzing completely the situation. Not that, with him, there was no place for intuition in mathematics. Quite the reverse. He recognized clearly that rigor is relative, depending on the domain of conceptions and the logical maturity of the student, and he was a master of diagnosis in determining what his students required or could receive, and what their minds must reject.

His contributions of the kind we have been considering were not confined to improving proofs already complete. He discovered gaps and filled them; as in the case of the theorem that a function which is harmonic in the neighborhood of a point, that point excepted, and becomes infinite there, must be of the form (when $n=2$ ):

$$
u=k \log r+\omega,
$$

where $\omega$ is harmonic at the point, also.

How extensive and how useful this work of Bôcher's was will become evident to any one who will turn to the writer's Funktionentheorie, volume I, and look up the references under Bôcher's name in the index. And what he did in this field, 
he did in others. His Algebra, for example, affords numberless instances in point.

In the early years of our professional lives we were in constant intercourse over such matters. Each of us was seeking to clarify and simplify his subject. Neither of us regarded the theory of functions of a real or of a complex variable as an end in itself, for each had his own ulterior uses for the theoryBôcher, his differential equations, both complex and real. In fact, for each of us the theory of functions was applied mathematics, and in presenting its subject matter and its methods to our students, our aim was to show them great problems of analysis, of geometry, and of mathematical physics which can be solved by the aid of that theory.

Bôcher was quick to grasp the large ideas of the mathematics that unfolded itself before our eyes in those early years. His attitude toward mathematics helped me to have the courage of my convictions. The Funktionentheorie is largely Bôcher's work, less through the specific contributions cited on its pages than through the influence he had exerted prior to 1897-long before a line of the book had been written. We worked together, not as collaborators, but as those who hold the same ideals and try to attain them by the same methods. It was constructive work, and in such Bôcher was ever eager to engage.

Harvard University,

William F. Osgood.

Cambridge, Massachusetts, December, 1918.

\section{A THEOREM ON LINEAR POINT SETS.}

BY DR. HENRY BLUMBERG.

(Read before the American Mathematical Society December 28, 1918.)

LET $A$ be any given linear point set. We define the "relative exterior measure* of $A$ in the interval $I$ " as $m_{e}(A, I) / l$, where $m_{e}(A, I)$ represents the exterior measure (Lebesgue) of the subset of $A$ in $I$, and $l$ is the length of $I$. We then define the "relative exterior measure of $A$ at the point $x$ " as

* Cf. Denjoy, Journal de Mathématiques, ser. 7, vol. 1 (1915), p. 130. 